\title{
O Uso do Portfólio em um Projeto de Pesquisa
}

\author{
SILZA MARIA PASELLO VALENTE \\ Professora do Departamento de Educação da \\ Universidade Estadual de Londrina \\ silzavalente@uol.com.br \\ LUCINEA APARECIDA DE REZENDE \\ Professora do Departamento de Educação da \\ Universidade Estadual de Londrina \\ lucinea@uel.br
}

\begin{abstract}
Resumo
O presente artigo relata a experiência de utilização do portfólio como ferramenta de avaliação no contexto do projeto de pesquisa "Leitura-Paixão: o impacto de uma situação diferenciada", desenvolvida no período de fevereiro de 2003 a fevereiro de 2005, na Universidade Estadual de Londrina. Participaram do estudo 11 estudantes, que deveriam entregar bimestralmente seus portfólios para análise; no entanto, eles só conseguiram realizar duas entregas. Da primeira entrega participaram os 11 alunos; da segunda, somente seis deles elaboraram portfólios, e, desses, apenas quatro responderam ao questionário de avaliação da experiência, que tinha como objetivo identificar as impressões acerca da construção do portfólio. Esses fatos evidenciam que, embora os participantes tenham aceitado a construção do portfólio como uma das formas de avaliação da sua participação no projeto, cinco deles acabaram por não entregá-lo, o que na análise da equipe coordenadora afigurou-se como uma das dificuldades da avaliação através de portfólios, ou seja, a fuga do autor ao ter ciência do envolvimento requerido. Por outro lado, as manifestações dos alunos evidenciam a motivação e o prazer despertados ao serem executadas as tarefas.
\end{abstract}

Palavras-chave: portfólio, avaliação, projeto de pesquisa, leitura.

\section{Resumen}

El presente artículo relata la experiencia de utilización del portfolio como herramienta de evaluación en el contexto del proyecto de investigación "Lectura - Pasión: el impacto de una situación diferenciada", desarrollada en el período comprendido entre febrero de 2003 a febrero de 2005, en la Universidad Estadual de Londrina (Paraná). Participaron del estudio 11 estudiantes, que deverian entregar bimestralmente sus portfólios para análisis; sin embargo solamente consiguieron realizar dos entregas. En la primera entrega participaron los onze alumnos; en la segunda, solamente seis de ellos elaboraron portfolios y de estos, cuatro contestaron al cuestionario de evaluación de la experiencia, cuyo objetivo era 
identificar las ideas y experiencias acerca de la elaboración del portfolio. Estos hechos manifiestan que aunque los participantes hayan aceptado la elaboración del portfolio como una de las formas de evaluación de su participación en el proyecto, cinco de ellos terminaron por no entregarlo, lo que en el analisis del equipo coordenador figuró como una de las dificultades de evaluación a través de portfolios, o sea, la huída del autor al darse cuenta del envolvimiento requerido. Por otro lado, las manifestaciones de los alumnos evidencian la motivación y el placer despertados por las tareas ejecutadas.

Palabras-clave: portfolio, evaluación, proyecto de investigación, lectura.

\begin{abstract}
The present article discusses the experiment of using a portfolio as an evaluation tool in the context of the research project "Reading - Passion: The impact of a unique situation", which was carried out between February 2003 and February 2005 at the State University of Londrina. Eleven students participated in this study. They were supposed to submit their portfolios for analysis every other month. However they only completed half of this task. The first time, all students participated; the second time, only six students handed in their material, and only four, out of these six, answered the questionnaire to assess the experiment. The purpose of the questionnaire was to identify students' impressions about the construction of the portfolio. These facts show that, although the participants had accepted the construction of portfolios as one of the forms for evaluating their participation in the project, five students did not complete the task. This was considered by the coordination staff as one of the difficulties posed by using portfolios as an evaluation instrument, i.e., students seem to quit when they realize how much involvement the task requires. On the other hand, some students did demonstrate their motivation and pleasure in constructing their portfolios.
\end{abstract}

Key words: portfolio, evaluation, research project, reading. 


\section{CONSIDERAÇÕES INICIAIS}

O termo portfólio é uma expressão inglesa relacionada com a avaliação/demonstração das produções no campo das artes (Crockett, 1998; Hernández, 2000). Embora nos anos 70 já se sugerisse a incorporação do portfólio na avaliação das aprendizagens, foi na década final do século $X X$, inicialmente nos ensinos europeu e americano, que o portfólio principiou por difundir-se na esfera escolar. Atribui-se a extensão do seu uso à percepção, no meio educacional, do seu potencial para subsidiar o processo avaliativo em uma perspectiva que viesse a superar a priorização dos aspectos quantitativos, nem sempre reveladores das diferentes capacidades estudantis.

Alves (2004) afirma que no Brasil não se tem tradição de utilizar esse tipo de instrumento para avaliação na Educação Superior; apenas alguns professores de cursos de formação docente utilizam-no para registro de ações e reflexões, especialmente quando se trata do Estágio Supervisionado. No entanto, percebe-se que esse panorama está mudando, pois relatos de uso do portfólio vêm sendo feitos através de artigos, livros e monografias (Rangel, 2003; Araújo, 2003; Villas Boas, 2002).

A literatura consultada evidencia que o portfólio pode ser construído em diferentes formatos e composto de diversos materiais, dependendo dos objetivos que se pretende atingir. Quando sua construção envolve elementos da informática, tem-se os webfólios - termo que, segundo Alves (2004), foi introduzido por Sueli Scherer -, apresentados em CD-ROM ou em uma homepage. Nesse caso, podem tanto contemplar a produção escolar do estudante no percurso da sua vida acadêmica quanto possibilitar elaborações criativas no contexto de uma determinada disciplina ou projeto.

Independentemente da forma como é elaborado, o portfólio "convida o estudante a retomar suas produções, fontes primárias, com um certo distanciamento, pois ao analisá-las começa a perceber o seu compromisso com o aprender, a sua modalidade de aprendizagem, o seu envolvimento com os temas estudados" (Rangel, 2003, p.151).

O portfólio, portanto, pode ser considerado uma ferramenta que tem o potencial de contemplar as produções dos alunos em um largo período de tempo, geralmente um período letivo, e de traduzir não somente sua maneira de pensar (dimensão cognitiva) como seus sentimentos e atitudes (dimensão afetiva) e sua maneira de agir (dimensão procedimental).

Com esse referencial, optamos por utilizar o portfólio como um dos instrumentos de avaliação no Projeto "Leitura-paixão: o impacto de uma 
situação diferenciada"1, em desenvolvimento na Universidade Estadual de Londrina. Esse projeto nasceu em razão da constatação, na tese de doutorado da autora e coordenadora do projeto (Rezende, 2002), da pouca e não-suficiente leitura na Graduação. Teve como objetivos: estudar leitura; oferecer aos estudantes múltiplas situações de contato com a leitura, junto a leitores e leitores-escritores, criando e/ou fortalecendo hábitos de cultivo da leitura; e verificar o impacto provocado nos alunos, em uma situação diferenciada da que ocorre em sala de aula, no que se refere à formação continuada do leitor.

Procuramos verificar por meio dos portfólios:

1) como o estudante estava se relacionando com as diferentes experiências de leitura, relatadas nas palestras mensais;

2) qual a participação discente no projeto, por meio do correio eletrônico, não somente em termos quantitativos, mas também qualitativos, ou seja, o estímulo evidenciado no compartilhar das produções;

3) como foi a participação do aluno nas reuniões semanais;

4) como se desenvolveu o processo de construção da escrita;

5) qual o nível de envolvimento afetivo com a leitura e com o projeto.

O sexto objetivo - descrever a percepção do processo ao se construir um portfólio, destacando os pontos positivos e negativos da experiência - era subjacente à proposta, mas não foi explicitado no momento inicial, pois não dizia respeito aos objetivos do projeto, mas aos de uma das pesquisadoras que atua na área de avaliação educacional.

\section{A EXPERIÊNCIA PASSO A PASSO}

Primeiro - Reunião da equipe coordenadora e participantes do projeto com a seguinte dinâmica:

- apresentação da proposta de trabalho/avaliação aos alunos;

- explicitação do significado do portfólio no processo avaliativo;

- apresentação dos objetivos do portfólio;

1 PROPPG/UEL, 22061/2002. 
- explicitação das diferentes possibilidades de apresentação, enfatizando que os estudantes deveriam estruturar o portfólio de modo que permitisse, aos professores, fazer comentários nos próprios textos;

- apresentação dos critérios de avaliação.

Aos alunos participantes, foi informado que poderiam estruturar o trabalho da maneira que julgassem mais adequada, inclusive construindo webfólios, visto que um deles dominava também as linguagens gráfica e informática. Houve uma boa receptividade e decidiu-se que, em uma próxima reunião, seria estabelecido o contrato para a elaboração do portfólio, contemplando-se elementos obrigatórios e outros optativos.

Segundo - Na reunião seguinte, ficou definido que, entre os elementos obrigatórios, os portfólios deveriam conter:

- relato e análise das palestras mensais;

- relato da participação através do correio eletrônico, transcrição das produções encaminhadas e comentários a respeito das produções recebidas que haviam causado maior impacto nos respectivos autores dos portfólios;

- relato dos temas abordados nas reuniões semanais e das decisões tomadas;

- transcrição das produções que os participantes desejassem contemplar no portfólio.

Ficou combinado usar diferentes componentes, considerados significativos pelos alunos, no processo de construção do conhecimento: fotos, pesquisas na Internet, jornais, revistas, relatos de leituras, comentários, relatos de experiências, desenhos, colagens, entre outros.

Foi apresentada e discutida a Ficha de Avaliação a ser preenchida, em conjunto, pela coordenadora e pelo aluno participante, contemplando os indicadores explicitados a seguir, em relação à elaboração do portfólio: $\left.1^{\circ}\right)$ cumpre os objetivos estabelecidos; $2^{\circ}$ ) apresenta os componentes comuns; $3^{\circ}$ ) apresenta outras fontes; $4^{\circ}$ ) apresenta produções pessoais; $5^{\circ}$ ) os textos produzidos evidenciam: clareza, coerência, criatividade, correção gramatical; $6^{\circ}$ ) evidencia reflexão a respeito das experiências vivenciadas; $7^{\circ}$ ) a organização do portfólio facilita a interação com a coordenadora; $8^{\circ}$ ) a forma de apresentação dos elementos constituintes permite sua pronta compreensão. 
Depois de preenchida essa ficha em conjunto com o aluno, coube à coordenadora fazer uma apreciação a respeito dos seguintes aspectos:

- Até que ponto $\mathrm{o}$ aluno evoluiu em relação às metas estabelecidas? (objetivos do projeto)

- Existem aspectos que devem ser aprofundados?

- Qual a apreciação geral a respeito do desempenho do aluno?

- Incluir outro aspecto, se necessário.

Terceiro - Recebimento e análise da primeira entrega dos portfólios. Foram entregues um webfólio em disquete e o endereço da homepage de um outro; os outros nove portfólios foram estruturados em pastas ou cadernos. Os alunos tiveram dificuldade em cumprir o prazo estipulado, o que provocou, em nosso cronograma, atraso na leitura e discussão. Nessa primeira entrega, percebeu-se que, de maneira geral, os objetivos estavam sendo contemplados e que os alunos estavam evoluindo, não somente na forma de expressão, mas também no aumento das leituras feitas. Foram dadas as indicações necessárias para que fossem superados os pontos deficitários, em sua maioria relatos factuais sem interferência analítica e ocorrência de erros gramaticais. Os portfólios foram devolvidos aos participantes no decorrer de uma reunião, e feitos comentários gerais pela equipe coordenadora a respeito dos pontos positivos e negativos detectados, sempre com a perspectiva de reforçar os aspectos positivos e orientar quanto à superação dos deficitários.

Quarto - Recebimento e análise da segunda entrega dos portfólios.

Ocorreu atraso na entrega prevista. Além disso, os alunos participantes do projeto estavam envolvidos em seus respectivos cursos com a entrega de trabalhos acadêmicos, bem como apresentações em eventos. Muitos alunos estavam sobrecarregados e, portanto, sem tempo para se empenharem na construção do portfólio.

Foram recebidos 6 portfólios: 5 deles estruturados em pastas ou cadernos e 1 em forma de homepage. Dos cinco primeiros entregues, apenas um deles deixou de atender plenamente aos objetivos (Indicador 1), pois não havia considerado a comunicação virtual através de e-mails, e todos apresentaram os elementos comuns (Indicador 2). Quanto aos demais indicadores, os mencionados portfólios foram assim avaliados: 
- Indicador 3: Apresenta outras fontes - As professoras consideraram que 4 portfólios apresentaram outras fontes, sendo 1 deles bastante rico nesse sentido, e 1 que apresentou poucas fontes.

- Indicador 4: Apresenta produções pessoais - A análise efetuada indicou que 4 portfólios apresentaram produções pessoais e 1 apenas um ensaio. A esse respeito a coordenadora observou que a participante estava evidenciando um "modelo bastante rígido de aprendizado".

- Indicador 5: Os textos produzidos evidenciam clareza, coerência, criatividade, correção gramatical - Em relação a esse indicador, as professoras analisadoras fizeram as seguintes observações a respeito do desempenho dos alunos participantes:

Participante 1 - Alguns textos pecam por uma certa falta de coerência, mas a participante evidencia que caminha para a autonomia da produção.

Participante 2 - Há, ainda, incorreções gramaticais; quanto aos demais itens foram atendidos. Os textos são de qualidade visto que expressam reflexão, ainda que contenham alguns erros gramaticais.

Participante 3 - As coordenadoras consideraram que os textos elaborados atenderam quase todos os itens do Indicador 5; apenas os aspectos referentes à correção gramatical ainda apresentaram alguns pontos a serem corrigidos.

Participante 4 - Os textos cumpriram todos os requisitos, na análise das coordenadoras

Participante 5 - Os textos cumpriram todos os requisitos, na análise das coordenadoras.

- Indicador 6: Evidencia reflexão a respeito do vivenciado - No entender das professoras, todos os portfólios apresentaram evidências de reflexão, sendo que um deles se destacou em relação aos demais.

- Indicador 7: A organização do portfólio facilita a interação com a coordenadora - As professoras consideraram que todos os participantes estruturaram seus portfólios atendendo a este quesito. 
- Indicador 8: A forma de apresentação dos elementos constituintes permite sua pronta compreensão - Na percepção das professoras, 4 portfólios atenderam plenamente esse quesito; 1 foi organizado de forma um pouco confusa, embora tenha sido possível perceber, segundo a análise das coordenadoras, "a construção processual de um conhecimento acerca da leitura e do projeto".

$\mathrm{O}$ quadro a seguir apresenta os comentários das professoras a respeito da estrutura dos portfólios e do desempenho dos participantes.

\section{COMENTÁRIOS DAS DOCENTES}

\begin{tabular}{|c|c|c|}
\hline PARTICIPANTES & ESTRUTURA DOS PORTFÓLIOS & $\begin{array}{l}\text { DESEMPENHO DOS } \\
\text { PARTICIPANTES } \\
\end{array}$ \\
\hline Participante 1 & $\begin{array}{l}\text { Portfólio bem resumido, sem originalidade } \\
\text { nem "vôos" maiores. Apresenta algumas } \\
\text { produções, sem situá-las. Apresentação } \\
\text { sem evidência de criatividade. }\end{array}$ & $\begin{array}{l}\text { A aluna vem se envolvendo } \\
\text { cada vez mais com a temática } \\
\text { leitura. }\end{array}$ \\
\hline Participante 2 & $\begin{array}{l}\text { Muitos textos sem continuidade, deixando } \\
\text { o leitor curioso quanto ao possível } \\
\text { desfecho. A aluna demonstrou empenho, } \\
\text { envolvimento. Registrou os aconteci- } \\
\text { mentos, refletiu acerca deles, evidenciou } \\
\text { interesse por leituras diversas. Deixou a } \\
\text { desejar quanto à organização. }\end{array}$ & $\begin{array}{l}\text { A aluna cresce significativa- } \\
\text { mente no processo reflexivo } \\
\text { acerca da leitura. }\end{array}$ \\
\hline Participante 3 & $\begin{array}{l}\text { Na Introdução o texto é confuso. Nas } \\
\text { produções seguintes os textos são claros, } \\
\text { coerentes, bem estruturados. Apresentam } \\
\text { algumas falhas no tocante à concordância e } \\
\text { ortografia. }\end{array}$ & $\begin{array}{l}\text { As produções do portfólio são } \\
\text { densas, ricas em detalhes, nos } \\
\text { emocionam. Constituem um } \\
\text { hipertexto, pois uma idéia } \\
\text { motiva a aluna a pesquisar } \\
\text { outro assunto e mais outro. } \\
\text { Excelente! Reflexivo! }\end{array}$ \\
\hline Participante 4 & $\begin{array}{l}\text { Embora a aluna relate apenas duas das } \\
\text { palestras realizadas até o momento da } \\
\text { entrega do portfólio, reflete a respeito do } \\
\text { vivenciado, incorpora a família em suas } \\
\text { descrições/reflexões, traz outras fontes de } \\
\text { informação. Mesmo incompleto em termos } \\
\text { dos objetivos, seu portfólio é criativo, } \\
\text { interessante, reflexivo. }\end{array}$ & $\begin{array}{l}\text { Portfólio rico, visto que traz } \\
\text { presente a alteração de visão } \\
\text { de mundo da autora em } \\
\text { relação à leitura }\end{array}$ \\
\hline Participante 5 & $\begin{array}{l}\text { O portfólio ainda está incipiente, mas a } \\
\text { aluna evidencia capacidade de reflexão e } \\
\text { interesse por fontes diversas. É criativa. }\end{array}$ & $\begin{array}{l}\text { A aluna avança em sua } \\
\text { expressão acerca da leitura. }\end{array}$ \\
\hline
\end{tabular}

A análise dos portfólios foi socializada em reunião com a presença das professoras e dos participantes. Os textos foram discutidos com os alunos, os quais tiveram a oportunidade de sanar as dúvidas que tinham com relação à compreensão do trabalho. 
O webfólio mereceu análise à parte. Devido às características da sua concepção e da formação do seu autor - pertencente à área de Artes contemplou mais a originalidade, a criatividade, os elementos gráficos e o processo de construção de escrita do participante. Seus textos foram mudando perceptivelmente de tamanho, de densidade. Suas análises foram se ampliando no decorrer do projeto. O participante, habituado a utilizar a linguagem gráfica, passou a incorporar, cada vez mais, a palavra em sua forma de ler e expressar o mundo e seus sentimentos acerca dele, o que pôde ser verificado através do acesso à sua homepage.

Quinto - Aplicação de um questionário aos participantes/construtores dos portfólios. Apenas 4 deles responderam às questões formuladas. As questões e as respostas serão explicitadas e analisadas a seguir.

Questão 1: "Como você se sentiu em relação às instruções para a elaboração do portfólio?" As respostas obtidas foram as seguintes:

Participante 1 - Foram claras, embora (eu tenha vindo) realmente a entender a tarefa quando comecei a construir o portfólio na disciplina de Didática.

Participante 2 - No começo da explicação, fiquei sem compreender o sentido de estar elaborando um portfólio. A compreensão ficou clara quando comecei a realizá-lo em uma outra disciplina do curso.

Participante 3 - A princípio, achei que tivesse entendido as instruções, mas na entrega do Portfólio as professoras deram a idéia de ao invés de fazer o Portfólio no caderno era melhor ter feito em uma pasta. Sinceramente, eu não gostei muito, pois achava que o Portfólio era uma coisa pessoal, então construí da minha maneira e não gostaria de mudá-lo. Mas acho que podemos conversar mais sobre o assunto.

Participante 4- No primeiro momento, achei que seria chato $e$ cansativo, que tomaria muito tempo, e realmente toma muito tempo, mas hoje já não acho chato e sim um exercício importante, que vai colaborar muito para minha formação, pois tenho muita vergonha de me expressar, e no portfólio posso escrever à vontade, ninguém vai estar me olhando. 
A análise das respostas evidencia, na perspectiva das docentes:

a) a dificuldade inicial de elaboração do portfólio;

b) a impressão - primeira - de ser uma exigência "chata" e cansativa;

c) a interpretação de que o portfólio é uma construção pessoal, e, portanto, o aluno deve ter liberdade para estruturá-lo à sua maneira.

Embora os participantes tivessem sido orientados no decorrer das reuniões, sendo que a primeira delas contou com a presença da mestranda Zilda de Araújo Rossi, autora de uma monografia sobre o tema, e as professoras terem se colocado à disposição para dirimir as dúvidas, ainda assim, duas alunas demonstraram dificuldade para compreender o trabalho.

Esse fato está, provavelmente, relacionado à consideração do portfólio como algo novo em termos de avaliação. Cumpre ressaltar que por estarem elaborando o portfólio em uma das disciplinas do curso de graduação facilitou a compreensão do processo. De toda forma, fica o alerta para a necessidade de orientações mais detalhadas, inclusive com leitura e discussão de textos, ao se pretender utilizar o portfólio como ferramenta avaliativa, visto que a dificuldade dos participantes não foi explicitada, desde o início, para a equipe coordenadora.

Quanto aos outros elementos das falas, a percepção de ser uma atividade "chata" e cansativa e do desejo do aluno de não-interferências quanto à forma escolhida para apresentar seu trabalho, também colocam pontos para a reflexão. O primeiro, no sentido de, ao se apresentar o portfólio, fazê-lo de maneira que não deixe essa impressão; e, o segundo, para que os alunos não se sintam atingidos em suas autodeterminações, quando os professores comentam que se o portfólio tivesse um outro formato, ficaria mais fácil a sua compreensão.

Um agravante no processo avaliativo foi o fato de as professoras não conseguirem realizar a avaliação em conjunto com os participantes (como havia sido inicialmente previsto). Por não disporem de um tempo maior para o projeto, os participantes não conseguiram ter um horário disponível para, em conjunto com as professoras, fazerem as avaliações. Com isso, pode-se deduzir que o fator tempo é uma variável que necessita ser vista com atenção, quando se incorpora o portfólio como ferramenta avaliativa. 
Questão 2: "Quais foram os pontos positivos no decorrer do processo de construção do portfólio." As respostas obtidas foram as seguintes:

Participante 1 - A construção do portfólio fica mais fácil quando se participa constantemente das reuniões, lêem-se livros; pode-se pontuar como positivo o nosso próprio desenvolvimento dentro do projeto.

Participante 2- $\grave{A}$ medida que fui construindo, pude perceber o caminho que eu já havia percorrido no projeto.

Participante 3 - Eu gostei muito de fazer meu portfólio; percebi que aos poucos fui mostrando um pouco de como sou intimamente, pois, às vezes, tenho vergonha de escrever o que sinto, com medo da avaliação do outro. Mas no Portfólio perdi um pouco desse medo e quanto mais eu lia mais eu queria escrever. Então um dos pontos mais positivo (sic) foi que consegui me expressar e outro ponto positivo é que aumentei muito meu conhecimento diante de tudo que pesquisei, dos emails que recebi e comentei, etc.

Participante 4 - Foi muito prazeroso construir o Portfólio; pude avaliar o meu crescimento no decorrer do projeto, foi muito gostoso e importante para mim ver o envolvimento da minha família e o quanto eu posso contribuir para a formação deles. É uma reflexão que me traz paz.

Ao analisarem as respostas dadas à segunda questão, as docentes perceberam uma mudança de atitude dos participantes no que diz respeito aos portfólios. À medida que foram se comprometendo com a sua construção, os participantes foram se tornando capazes de apreender o significado maior da ferramenta: a possibilidade de reflexão sobre o fazer, a importância do envolvimento cognitivo e afetivo no processo de construção. De cansativo, "chato", tornou-se prazeroso, reflexivo, criativo, envolvente.

Questão 3: "Quais os aspectos que consideraram negativos (dificultadores) no decorrer do processo de construção do portfólio?" Os participantes assim se manifestaram: 
Participante 1 - Não sei se essa resposta se encaixa na questão, mas o que considero negativo, até como incentivo, é que, enquanto eu e algumas colegas se preocupam (sic) com a entrega do portfólio no dia combinado, tem pessoas que nem chegam a entregá-lo ou entregam meses após a data, ficando evidenciado que essas pessoas não estão construindo seu portfólio dia-a-dia.

Participante 2 - A dificuldade que considerei foi não compreender qual era o significado daquele trabalho, ou seja, qual era o objetivo. E também a insegurança de (não) saber se aquilo que estava fazendo era certo.

Participante 3 - Não respondeu.

Participante 4 - A única dificuldade que encontrei foi a falta de tempo, pois a construção do portfólio exige tempo e dedicação, $e$ a nossa vida acadêmica nos exige muito, não nos deixando tempo livre, mas não vejo isso como ponto negativo e sim como obstáculos que encontramos sempre em nossos caminhos, e o que é mais difícil sempre tem um gostinho mais saboroso.

As docentes detectaram que as respostas à questão 3 apontam como fatores que dificultam o trabalho: a falta de pontualidade, de tempo e de compreensão. Esses aspectos já foram considerados no decorrer dos comentários relativos às questões anteriores. Cumpre ressaltar que a falta de pontualidade causa sérios transtornos. É um item que necessita, portanto, constar em um contrato pedagógico a ser estabelecido entre professor e alunos.

Questão 4: “Como você se sentiu antes da construção do portfólio, no decorrer do processo de construção do mesmo e ao receber o feedback das professoras?" Foi assim respondida pelos participantes: 


\section{Construção do portfólio}

\begin{tabular}{|c|c|c|c|}
\hline & ANTES & DURANTE & APÓS \\
\hline Participante 1 & $\begin{array}{l}\text { Via a construção como uma obrigação, } \\
\text { mais uma tarefa acadêmica. }\end{array}$ & $\begin{array}{l}\text { Percebi que não foi ruim; pelo contrário, } \\
\text { tive prazer ao construí-lo, procurei } \\
\text { materiais que iriam me ajudar na sua } \\
\text { construção. }\end{array}$ & $\begin{array}{l}\text { É gratificante quando o recebemos, ver que em algumas anotaçóes } \\
\text { nossas professoras também acham interessante e nos incentivam; } \\
\text { por outro lado, também é bom analisar nossos erros e saber como } \\
\text { fazer da próxima vez. E ao analisar o portfólio do amigo vemos que } \\
\text { cada um possui um conceito de leitura, e por isso cada portfólio é } \\
\text { construído de uma maneira diferente e individual. }\end{array}$ \\
\hline Participante 2 & $\begin{array}{l}\text { Por não estar compreendendo o real } \\
\text { objetivo do portifólio (sic), via apenas } \\
\text { como uma cumprissão (sic) de tarefa.. }\end{array}$ & $\begin{array}{l}\text { À medida que fui construindo, a elaboração } \\
\text { foi tornando-se }(\mathrm{sic}) \text { significativa, pois como } \\
\text { já disse tive a oportunidade de perceber o } \\
\text { meu desenvolvimento dentro do projeto. }\end{array}$ & $\begin{array}{l}\text { Após a primeira avaliação do portfólio a participante enviou e-mail } \\
\text { para o grupo com o intuito de compartilhar as expressões (sic) que } \\
\text { obtive ao receber meu portfólio. } \\
\text { É um longo texto e a participante o incorporou ao questionário } \\
\text { aplicado pelas professoras ao final da segunda entrega. Nele a a } \\
\text { participante afirma: não gostei do retrato que delineei no portifólio } \\
\text { (sic), acho que não estruturei meu pensamento, o trabalho não ficou } \\
\text { organizado, sistematizado; no entanto a construção da segunda } \\
\text { parte desse ajudou-me a refletir (a respeito) da imagem que estou } \\
\text { passando às pessoas, ou seja, proporcionou uma leitura da minha } \\
\text { pessoa. } \\
\text { [...]o projeto Leitura-Paixão [..] foi um dos primeiros locais onde } \\
\text { pude expressar meus pensamentos, onde minha maneira de pensar } \\
\text { foi respeitada e cobrada para ser registrada [...] aprendi mil coisas } \\
\text { com o projeto; umas significativas como estudante e outras como } \\
\text { ser humano. }\end{array}$ \\
\hline Participante 3 & $\begin{array}{l}\text { Quando as professoras [...] nos propôs } \\
\text { (sic) fazermos o Portfólio eu não gostei } \\
\text { muito; comecei a colocar impecilhos (sic) } \\
\text { dizendo que eu não tinha tempo (realmente } \\
\text { na época eu estava muito atarefada) que ia } \\
\text { ser um trabalho desgastante, etc. Até que } \\
\text { resolvi deixar para fazê-lo nas minhas } \\
\text { férias; durante o período de aula ia } \\
\text { guardando os e-mails já comentados e } \\
\text { depois montei o Portfólio, fui fazendo } \\
\text { algumas leituras durante as férias e } \\
\text { pesquisando o que mais me interessava.. }\end{array}$ & $\begin{array}{l}\text { Como já comentei, depois que iniciei meu } \\
\text { portfólio até a coisa andou. Fiz tudo com } \\
\text { muito prazer, procurei expor meus } \\
\text { sentimentos e admito: muitas vezes me } \\
\text { emocionei e me peguei chorando. As vezes } \\
\text { lia o que eu escrevia para minha mãe, e ela } \\
\text { sempre dizia que estava bom; como sempre } \\
\text { a D. Maria me incentivando. Para concluir, } \\
\text { sei que cometi vários erros, mas mesmo } \\
\text { assim me senti muito feliz ao concluir esse } \\
\text { precioso trabalho, pois é errando que se } \\
\text { aprende. }\end{array}$ & $\begin{array}{l}\text { Quando as professoras entregaram os Portfólios ouvi tudo que elas } \\
\text { falaram com muito carinho, pois sei que é para melhorarmos } \\
\text { intelectualmente e me senti aliviada de ter concluído um trabalho } \\
\text { que fiz com muito gosto. Só gostaria de continuar fazendo da } \\
\text { mesma maneira que iniciei, na mesma sequiência. Eu não separei } \\
\text { por eventos, livros, e-mails, mas sim pelo tempo cronológico } \\
\text { (datas). Mas na próxima reunião podemos conversar sobre o } \\
\text { assunto para que eu possa continuá-lo. }\end{array}$ \\
\hline $\begin{array}{l}\text { Participante } 4 \\
\end{array}$ & Não respondeu & \begin{tabular}{|l|} 
Não respondeu \\
\end{tabular} & Não respondeu \\
\hline
\end{tabular}


O intuito da terceira questão foi o de apreender a dimensão afetiva dos participantes, seus sentimentos antes e durante a elaboração dos portfólios e após a sua entrega.

É claramente perceptível nas respostas que os participantes foram se comprometendo emocional e cognitivamente com o processo de elaboração, chegando um deles a envolver a própria família em sua atividade. Percebe-se, também, que foi compreendida a dimensão inclusiva dessa ferramenta de avaliação, que busca intensificar o envolvimento dos alunos em seus processos de aprendizagem; enfim, que busca orientar, dialogar, ouvir, compreender, apontar possibilidades, evidenciar que existem diferentes maneiras de demonstrar o que se aprendeu.

\section{CONSIDERAÇÕES FINAIS}

A propósito da pesquisa desenvolvida, deseja-se ressaltar que a avaliação através de portfólios, apesar de ser ainda incipiente em nosso sistema educacional, tem motivado alunos e professores a incorporar essa ferramenta, por considerarem que ela tem a possibilidade de harmonizar os aspectos quantitativo e qualitativo em uma perspectiva processual que não se traduz somente em notas, mas principalmente em análises e reflexões por parte de professores e alunos.

Um dos aspectos que merece ser enfatizado, no entender das pesquisadoras, é que o portfólio requer a apropriação dos alunos por esse instrumento de avaliação em uma perspectiva de contribuição para o autoconhecimento e para a aprendizagem de forma prazerosa, ainda que trabalhosa. Talvez o mais importante dos aspectos seja o fato de os portfólios analisados terem sido construídos no próprio caminhar dos discentes. Cada participante teve a oportunidade de estruturar seu portfólio da forma como achou conveniente. Embora existissem elementos a serem seguidos, eles foram incorporados da forma considerada mais adequada, em consonância com o que nos diz o poeta Antonio Machado (1973, p. 158): 


\author{
Caminhante, são teus rastos \\ o caminho, e nada mais; \\ caminhante, não há caminho, \\ faz-se caminho ao andar. \\ Ao andar faz-se o caminho, \\ e ao olhar-se para trás \\ $v \hat{e}$-se a senda que jamais \\ se há de voltar a pisar. \\ Caminhante, não há caminho, \\ somente sulcos no mar.
}

Cumpre enfatizar que a incorporação do portfólio ao processo avaliativo dos participantes do projeto não teve a intenção de validar essa ferramenta avaliativa, pois seu uso no cotidiano escolar já está validado, como evidenciam os trabalhos a respeito. Ou seja, o que estava em questão não era a ferramenta em si, mas qual a melhor forma de utilizá-la para possibilitar a apreensão não só do progresso dos participantes no processo de construção da escrita e no relacionamento com as diferentes formas de linguagem, mas também ensejasse perceber $o$ envolvimento emocional/atitudinal dos alunos em relação às diferentes possibilidades de leitura.

Os dados coletados possibilitaram captar elementos valiosos para implementar a utilização do portfólio, de maneira a superar os aspectos considerados negativos na opinião dos participantes. Além disso, no que tange aos outros aspectos destacados - progresso na aquisição da escrita e envolvimento emocional -, o portfólio evidenciou ser uma ferramenta avaliativa assaz rica, pois foi possível perceber como os participantes foram, no decorrer do projeto, desenvolvendo a capacidade de se expressar não só por meio de palavras, mas também por outras linguagens, assim como foram fraternalmente se envolvendo uns com os outros, com a coordenadora e com o projeto como um todo.

Um dos exemplos mais eloqüentes talvez seja o do autor da homepage, habituado, conforme ele mesmo disse, a expressar-se por meio de outras linguagens, e com esse projeto ficou estimulado a produzir textos escritos, fazendo-o com propriedade e profundidade temática. No transcorrer das reuniões, o participante sempre falava de como estava se sentindo feliz por conseguir se expressar por meio das palavras, trazendo à tona suas reflexões, angústias, vivências em geral, e poder compartilhá-las com os demais.

Em um dos textos de sua autoria, constante na homepage e intitulado "Quando a leitura é uma questão de sobrevivência", o autor afirma, referindo-se a si mesmo, como se fosse um terceiro personagem: o hábito da 
leitura sempre foi muito maior do que o da escrita. Na verdade, ele sempre preferiu o desenhar ao escrever. No entanto, o estímulo para a escrita foi tão intenso que ele produziu e alocou no site os seguintes textos: "Bar da sexta", "Circularidade", "O passageiro", "Quando as mães choram", "Doce suicídio", "Correspondência", "Quando a leitura é uma questão de sobrevivência" e "Análise do Jarro Azul".

Quanto aos demais participantes, percebeu-se claramente o aumento do número de trocas de correspondências via e-mail, o interesse pela leitura e pela elaboração de textos, o aprofundamento da capacidade reflexiva, além do incremento do interesse por pesquisar assuntos relacionados com as temáticas discutidas nas reuniões.

Ainda permanecem nas produções dos participantes problemas formais relacionados à escrita, que necessitam ser retomados na seqüência do Projeto; no entanto, o objetivo maior das pesquisadoras, ou seja, criar estratégias para levar os participantes a se interessarem pela leitura e escrita, foi plenamente atingido.

\section{REFERÊNCIAS BIBLIOGRÁFICAS}

ALVES, L. P. Portfólios como instrumentos de avaliação dos processos de ensinagem. Disponível em: http://www.anped.org.br/26/trabalhos/ leonirpessatealves.rtf. Acesso em: 5 jan. 2004.

ARAÚJO, Z. R. O portfólio: reconstrução de uma experiência vivida. Monografia. Apresentada à Universidade Estadual de Londrina/ Departamento de Educação. Curso de Especialização em Avaliação Educacional, 2003. 127 p.

CROCKETT, T. The portfólio journey: a creative guide to keeping studentmanaged portfolios in the classroom. Englewood Colorado: Teacher Ideas. A Division of Libraries Unlimited, 1998.

HERNÁNDEZ, F. Cultura visual, mudança educativa e projeto de trabalho. Trad. Jussara Haubert Rodrigues. Porto Alegre: Artes Médicas Sul, 2000.

MACHADO, A. Poesias completas. 14 ed. Madri: Calpe, 1973.

RANGEL, J. N. M. O Portfólio e a Avaliação no Ensino Superior. Estudos em Avaliação Educacional, São Paulo, n. 28, p. 145-160, jul./dez. 2003. 
REZENDE, L. A de. Ler ou pensar: uma escolha a ser feita na Graduação? Estudo de caso. Piracicaba, 2002. Tese (dout.) Universidade Metodista de Piracicaba - Unimep.

VILLAS BOAS, B. M. de F. Portfólio, avaliação e trabalho pedagógico. Campinas: Papirus, 2002. (Coleção Magistério: formação e trabalho pedagógico)

Recebido em: junho 2005

Aprovado para publicação em: setembro 2005 